\title{
An unusual case of POEMS syndrome
}

\author{
Mani Gupta, Rajesh Verma, Ravindra Kumar Garg, Maneesh Singh \\ Department of Neurology, Chhatrapati Shahuji Maharaj Medical University, Lucknow, Uttar Pradesh, India
}

Correspondence to Professor Rajesh Verma, drrajeshverma32@yahoo.com

\section{Summary}

We report a 48-year-old man, a farmer, presenting with chronic sensori-motor polyneuropathy. Electrophysiology revealed demyelinating type of neuropathy. Immunoelectrophoresis for monoclonal protein was negative; however, plasmacytoma was discovered on spine imaging. After receiving radiotherapy and chemotherapy over past 9 months there has been a considerable improvement in patient's disability. This case highlights the role of skeletal survey in evaluation of chronic demyelinating neuropathy.

\section{BACKGROUND}

Chronic inflammatory demyelinating polyneuropathy (CIDP) can be idiopathic or secondary to a wide spectrum of diseases including monoclonal gammopathy of unknown significance (MGUS), POEMS (polyneuropathy, organomegaly, endocrinopathy, $M$-protein, skin changes) syndrome, vasculitis, collagen vascular diseases (especially systemic lupus erythematosus), chronic hepatitis, HIV infections and Hodgkin's disease. In a study of 65 cases of CIDP by Wadwekar et al, ${ }^{1} 25$ cases (38.5\%) were secondary. Four cases in this case series were diagnosed as POEMS syndrome. POEMS syndrome is a smouldering disease, polyneuropathy being the initial presentation while the systemic manifestations appear later in course. Thus, it requires a high degree of clinical suspicion to detect this condition. It is imperative to rule out plasma cell dyscrasia before labelling a chronic demyelinating polyneuropathy as idiopathic because treatment regimens for the two conditions are entirely different. The monoclonal protein in POEMS is of small size and hence may not be detectable even by immunofixation method in up to $10 \%$ of cases. ${ }^{2}$ Diagnosis in such cases would depend on demonstration of skeletal lesions. The 'mini brain' appearance of the lesions in the spine on MRI has been reported to be quite pathognomonic of plasmacytoma. ${ }^{3}$ This case report is intended to highlight the importance of performing skeletal imaging in all cases of CIDP, even in the absence of a monoclonal protein.

\section{CASE PRESENTATION}

A 48-year-old man presented with sensori-motor quadriparesis since 4 years. The disease initially manifested with positive sensory symptoms, including, paresthesias, dysesthesias followed by weakness in the distal lower limbs. The weakness then progressed to proximal lower limbs followed by distal upper limbs. The patient had moderate-to-severe pain in the upper back around the scapula, non-radiating and worsening on movement. There were no complaints of sphincter abnormality, band-like sensation or a sensory level. The patient had patchy hyperpigmentation of the skin and severe weight loss since the onset of illness.

The general examination revealed skin hyperpigmentation and mild hepatosplenomegaly. The motor system assessment depicted generalized wasting, hypotonia, and power was grade $4 / 5$ in all extremities, worse distally. Deep tendon reflexes were diminished to absent with bilateral plantars flexor. Sensory examination showed graded loss of fine touch and pain in all limbs in a glove-and-stocking pattern. Vibration and joint position were impaired in all limbs and Romberg's test was positive. There was tenderness over the lower cervical and upper thoracic spine.

\section{INVESTIGATIONS}

Haematological parameters and biochemical evaluation including haemoglobin, leucocyte count, platelet count, renal function test, liver function test, serum electrolytes and blood glucose were within the normal limit.

Nerve conduction study showed marked prolongation in distal latency (right median: $6.90 \mathrm{~ms}$, left median: $8.1 \mathrm{~ms}$, left ulnar: $7.2 \mathrm{~ms}$ ) and severe slowing in conduction velocity (right median: $23 \mathrm{~m} / \mathrm{s}$, left median: $10.9 \mathrm{~m} / \mathrm{s}$, left ulnar: $8.2 \mathrm{~m} / \mathrm{s}$ ). There was severe loss of amplitude in all three nerves (distal compound muscle action potential (CMAP) right median: $0.1 \mathrm{mV}$, left median: $0.4 \mathrm{mV}$, left ulnar: $0.1 \mathrm{mV}$ ). The right ulnar CMAP, bilateral median and ulnar sensory nerve action potentials (SNAP) and bilateral common peroneal and tibial CMAPs and sural SNAPs were not recordable.

Cerebrospinal fluid analysis disclosed albuminocytological dissociation. Serology for HIV was nonreactive. Antinuclear antibody and rheumatoid factor were absent. Serum immunoelectrophoresis test did not reveal M-protein. Bone marrow aspiration and trephine biopsy did not show features of multiple myeloma.

Radiography showed a large lytic lesion with sclerotic margins involving the first, second, third thoracic vertebra and a similar but smaller lesion in third lumbar vertebrae (figure 1). Radiography of the skull was normal. MRI of the spine demonstrated central hypointensity with surrounding signal void on T1-weighted image and central hyperintensity with a peripheral rim of low signal intensity on T2-weighted images (figure 2). CT-guided biopsy from the lumbar vertebrae revealed atypical plasma cells with altered nuclear:cytoplasmic ratio and mitotic figures suggestive of plasmacytoma (figure 3 ). 


\section{BMJ Case Reports}

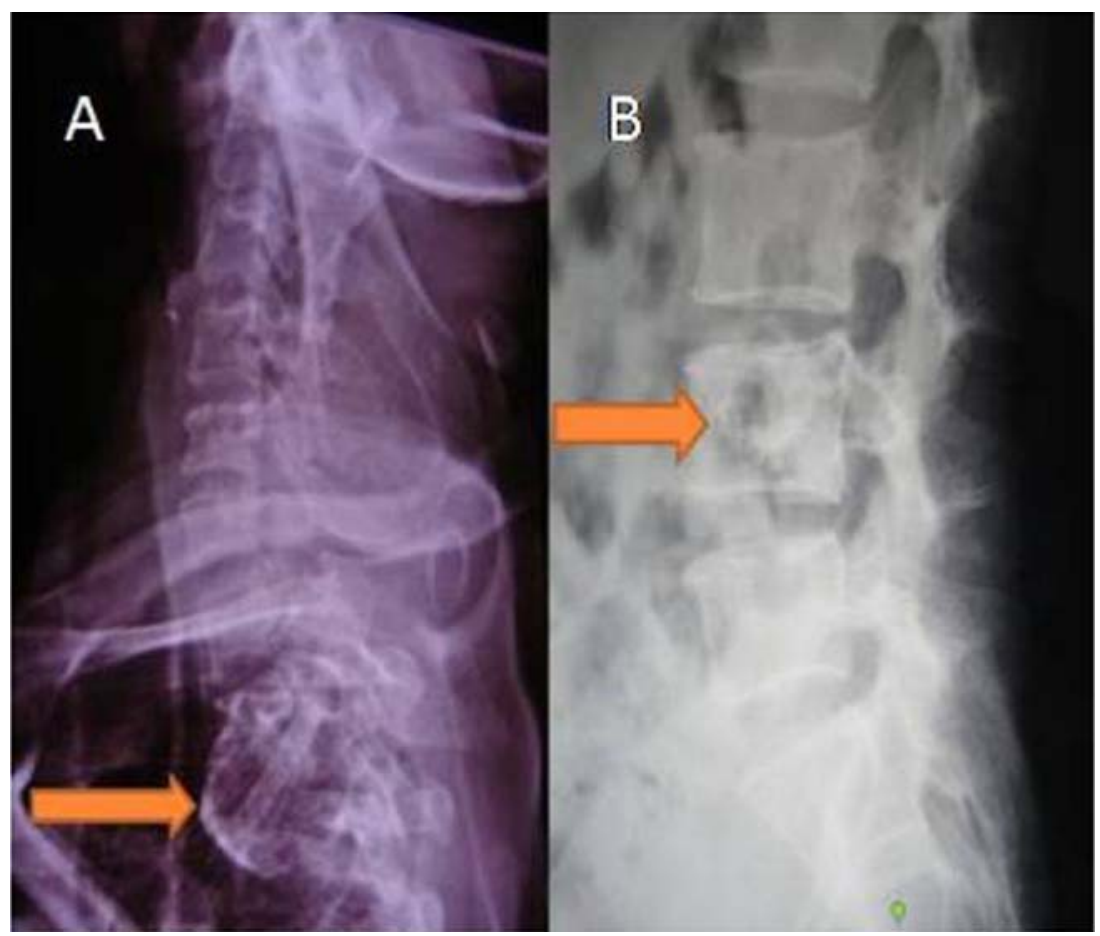

Figure 1 (A) Radiograph of cervico-thoracic spine showing lytic lesion with sclerotic margin involving the first, second and third thoracic vertebrae (arrow). (B) Radiographic study of lumbosacral spine demonstrating lytic lesion with sclerotic margin in third lumbar vertebrae (arrow).

\section{TREATMENT}

The patient has been on oral melphalan $\left(10 \mathrm{mg} / \mathrm{m}^{2}\right.$ body surface area (BSA)) plus oral dexamethasone $(40 \mathrm{mg} /$ day) on days $1-4$ of every 28 days for the last 9 months. He also received radiotherapy for thoracic spine lesions.

\section{OUTCOME AND FOLLOW-UP}

There was significant improvement in patient's sensory complaints and weakness with attainment of independence in activities of daily living.

\section{DISCUSSION}

This case highlights an atypical presentation of POEMS syndrome. The patient in our case had presented with a long-standing sensory predominant polyneuropathy. The demyelinating nature of neuropathy was established on nerve conduction study which was further substantiated by the presence of albumino-cytological dissociation in cerebrospinal fluid. The predominant involvement of distal lower limbs was indicative that this may not be an idiopathic CIDP. The prolongation in distal latencies was significant, though, not very severe. In addition there was

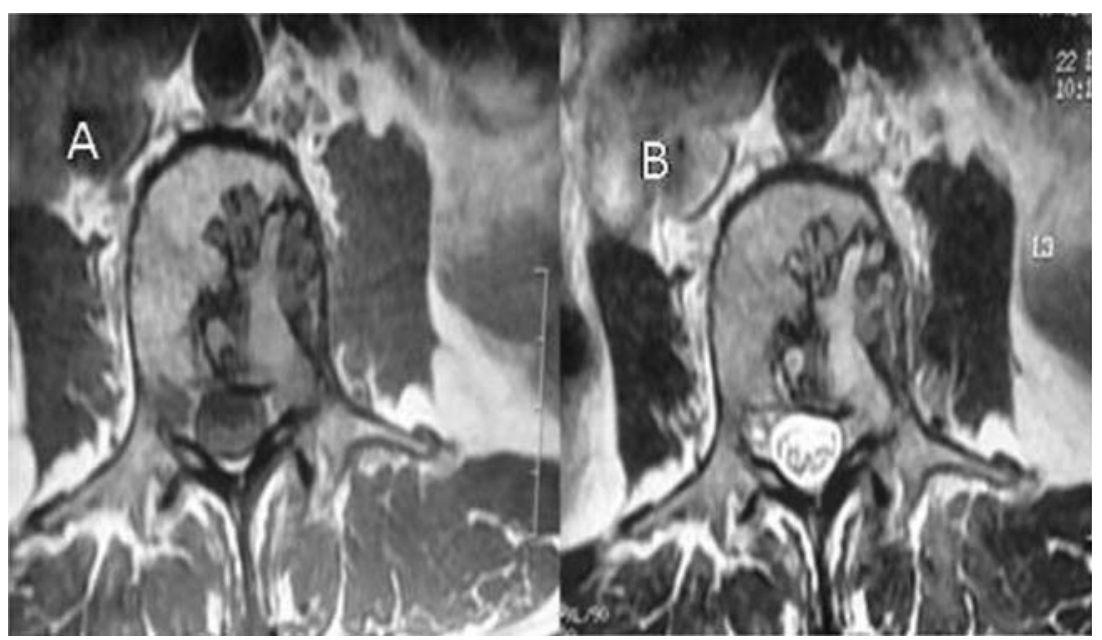

Figure 2 (A) T1-weighted (T1W): hypointense lesion on T1W with surrounding signal void in a convoluted pattern. (B) T2-weighted: central hyperintensity surrounded by a peripheral convolution of low signal intensity on MRI of third lumbar vertebrae. (A) and (B) Mimic sulci and gyri of brain and hence known as mini brain sign. 


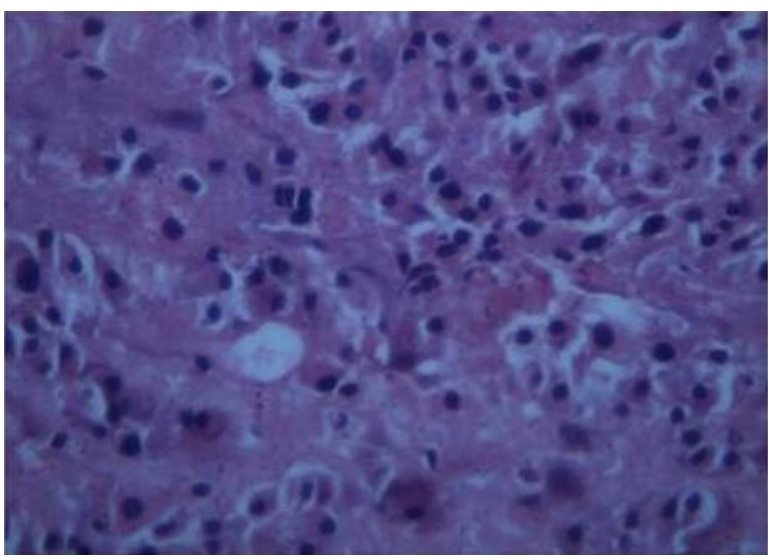

Figure 3 Biopsy histology showing plasma cells with altered nuclear:cytoplasmic ratio and mitotic figures suggestive of plasmacytoma.

marked slowing in the conduction velocity and severe loss of distal amplitude in the bilateral median and left ulnar nerves. The terminal latency index was 0.68 in the right median and 1.01 in the left median nerves. The electrophysiological findings were suggestive of more severe involvement of intermediate segment rather than the distal part of nerve trunks. This pattern of clinical presentation and electrophysiological profile in a chronic demyelinating polyneuropathy has been found to be consistent with POEMS syndrome. The differentiating features between POEMS syndrome and idiopathic CIDP have been summarized in table $1 .^{4}$ The immunoelectrophoresis was negative. The lytic lesions in the spine made us further suspicious about an underlying plasma cell dyscrasia and the 'mini brain' appearance of these lesions on MRI almost ascertained plasmacytoma as the aetiology. Lytic lesions of no other aetiology produce this kind of appearance on MRI as does plasmacytoma. The diagnosis was further confirmed on CT-guided vertebral biopsy. The major (polyneuropathy and monoclonal plasma cell proliferative disorder) and minor criteria (by presence of mixed sclerotic and lytic bone lesions, skin hyperpigmentation, hepatosplenomegaly) for POEMS syndrome were fulfilled, as defined by Dispenzieri et al. ${ }^{5}$

The predominant presentation of POEMS syndrome is polyneuropathy followed by organomegaly, endocrinopathy, sclerotic bone lesions, skin lesions and others. The monoclonal protein in this condition is usually less than $2 \mathrm{~g} / \mathrm{dl}$ and negative in $10 \%$ of cases even by immunofixation method. The bone lesions, though usually of sclerotic variety, can be both mixed sclerotic with lytic component or purely lytic.

There are no randomized controlled trials available for the treatment of POEMS syndrome; however, therapies which definitely benefit include radiotherapy, alkylatorbased therapy and corticosteroids. The solitary plasmacytomas are treated with radiotherapy while the widespread plasmacytomas are treated with systemic therapy. In a study of 31 patients by Jian Li et a ${ }^{8}$ with melphalan and corticosteroids combination regimen there was $100 \%$ neurological response, $77.4 \%$ subjects responding at 3 months. All patients remained alive with neurological relapse in only three cases. High-dose chemotherapy with stem cell transplantation is another emerging modality with minimal peri-transplant complications, and a substantial and sustained improvement in neuropathy. ${ }^{9}$

\section{Learning points}

- POEMS (polyneuropathy, organomegaly, endocrinopathy, M-protein, skin changes) syndrome is a rare condition with demyelinating polyneuropathy as predominant mode of presentation. It requires a high degree of suspicion to diagnose this condition.

- The clinical and electrophysiological profile can help to predict that POEMS syndrome is the underlying aetiology in a chronic demyelinating polyneuropathy.

- The monoclonal protein in POEMS syndrome is of small size; hence, it may not be evident in $10 \%$ of cases even on immunofixation.

- The diagnosis of an underlying plasma cell dyscrasia would be missed if a clinician relied solely on detection of monoclonal protein. This case highlights the importance of performing a skeletal imaging to uncover an underlying plasmacytoma even if monoclonal protein is absent.

- The 'mini brain' appearance of spine lesions on MRI is quite pathognomonic of plasmacytoma, even obviating the need for a biopsy.

Table 1 Clinical and electrophysiological differentiation between polyneuropathy in POEMS and CIDP

\begin{tabular}{|c|c|c|}
\hline Characteristics & POEMS syndrome & CIDP \\
\hline Clinical & $\begin{array}{l}\text { Neurological } \\
\text { 1. Severe leg pain }(p<0.001) \\
\text { 2. Muscle atrophy }(p=0.005) \\
\text { 3. Distal dominant muscle weakness } \\
\text { Presence of systemic manifestations (organomegaly, endocrinopathy, } \\
\text { skin changes, effusions, oedema, lymphadenopathy) }\end{array}$ & $\begin{array}{l}\text { Usually sensory symptoms are less prominent and the weakness } \\
\text { diffusely involves the proximal and distal limbs }\end{array}$ \\
\hline Electrophysiological & $\begin{array}{l}\text { Demyelination predominantly in the nerve trunk } \\
\text { 1. Usually less prominent prolongation of distal latency (mean } 5.6 \mathrm{~ms} \\
\text { vs } 8.1 \mathrm{~ms} ; p<0.001 \text { ) and higher terminal latency index }(T L I)^{6}(0.42 \\
\text { vs } 0.33 ; p=0.006) \text { in the median nerves } \\
\text { 2. Unrecordable tibial and sural sensory responses } \\
\text { 3. Axonal loss in lower limbs }\end{array}$ & $\begin{array}{l}\text { All three patterns of involvement possible } \\
\text { 1. Distal: markedly prolonged distal latency (DL) with less prominent } \\
\text { decline in conduction velocity (CV) and absence of temporal } \\
\text { dispersion (TD) and conduction block (CB). } \\
\text { 2. Intermediate: marked slowing of CV with severe CB and TD but } \\
\text { lesser prolongation of DL } \\
\text { 3. Diffuse: both severe prolongation in DL and severe abnormality in } \\
\text { CV, CB and TD }\end{array}$ \\
\hline
\end{tabular}

$\mathrm{TLI}=$ distal conduction distance $(\mathrm{mm}) /$ forearm conduction velocity $(\mathrm{m} / \mathrm{s}) /$ distal latency $(\mathrm{ms})$. 


\section{BMJ Case Reports}

\section{Competing interests None.}

Patient consent Obtained.

\section{REFERENCES}

1. Wadwekar V, Kalita J, Misra UK. Does the chronic inflammatory demyelinating polyradiculoneuropathy due to secondary cause differ from primary? Neurol India 2011;59:664-8.

2. Dispenzieri A. POEMS syndrome. Hematology Am Soc Hematol Educ Program 2005;360-7.

3. Nancy MM, Clyde AH, William JR, et al. The 'mini brain' plasmacytoma in a vertebral body on MR imaging. AJR Am J Roentgenol 2000;175:261-3

4. Nasu S, Misawa S, Sekiguchi Y, et al. Different neurological and physiological profiles in POEMS syndrome and chronic inflammatory demyelinating polyneuropathy. J Neurol Neurosurg Psychiatry 2012;83:476-9.
5. Dispenzieri A, Kyle RA, Lacy MQ, et al. POEMS syndrome: definitions and long-term outcome. Blood 2003:101:2496-506.

6. Shahani BT, Young RR, Potts F, et al. Terminal latency index (TLI) and late response studies in motor neuron disease (MND), peripheral neuropathies and entrapment syndromes [abstract]. Acta Neurol Scand 1979;73:118.

7. Kuwabara S, Ogawara K, Misawa S, et al. Distribution patterns of demyelination correlate with clinical profiles in chronic inflammatory demyelinating polyneuropathy. J Neurol Neurosurg Psychiatry 2002;72:37-42. doi: 10.1136/jnnp.72.1.37

8. Jian L, Wei Z, Li J, et al. Combination of melphalan and dexamethasone for patients with newly diagnosed POEMS syndrome. Blood 2011;117:6445-9.

9. Peggs KS, Paneesha S, Kottaridis PD, et al. Peripheral blood stem cell transplantation for POEMS syndrome. Bone Marrow Transplant 2002:30:401-4.

This pdf has been created automatically from the final edited text and images.

Copyright 2012 BMJ Publishing Group. All rights reserved. For permission to reuse any of this content visit http://group.bmj.com/group/rights-licensing/permissions.

BMJ Case Report Fellows may re-use this article for personal use and teaching without any further permission.

Please cite this article as follows (you will need to access the article online to obtain the date of publication).

Gupta M, Verma R, Garg RK, Singh M. An unusual case of POEMS syndrome. BMJ Case Reports 2012;10.1136/bcr-02-2012-5885, Published XXX

Become a Fellow of BMJ Case Reports today and you can:

- Submit as many cases as you like

- Enjoy fast sympathetic peer review and rapid publication of accepted articles

- Access all the published articles

Re-use any of the published material for personal use and teaching without further permission

For information on Institutional Fellowships contact consortiasales@bmjgroup.com

Visit casereports.bmj.com for more articles like this and to become a Fellow 